\title{
TEST OF H-20 SEPTUM WIRES
}

\section{BOOSTER TECHNICAL NOTE \\ NO. 157}

\author{
E. RODGER and V. BADEA
}

FEBRUARY 28, 1990

ALTERNATING GRADIENT SYNCHROTRON DEPARTMENT BROOKHAVEN NATIONAL LABORATORY

UPTON, NEW YORK 11973 


\section{Description of Tests}

During the months of October and November 1989 tests of 0.002 in dia $x 4$ in length tungsten wires were performed.

a) The wires were taken out from H-20 electrostatic septum after being exposed to the beam. Residual radiation level was 0.8 m R/HR@12 in. Location of wires removed was as follows:

1. One piece from upstream (specimen 1)

2. One piece from the middle (specimen 2)

3. One piece from downstream (specimen 3 )

b) In addition a number of 6 samples of virgin wires was tested under similar conditions to determine whether any changes occurred due to the beam exposure.

c) The tests performed followed the General Tensile Test Procedure of: Automated Materials Testing system U4.05a (see annexes \# $1 \& 2$ ).

d) Several attempts were made to determine whether changes took place in the structure of tungsten wire after being exposed to the beam. To accomplish that, the wire samples were photographed as follows: (see annexes A, B, C, $\mathrm{D} \& \mathrm{E})$.

- wire unmounted - mag. $400 x$, photo A (photo taken $\approx 3 / 4$ " from end of wire of an untouched area by the beam.)

- wire unmounted - mag 400x, photo $\mathrm{B}, \mathrm{C} \& \mathrm{D}$ (photos taken $\approx$ at center, area touched by the beam)

- wire mounted and polished - mag 400x, photo E. (Photo taken 1 1/2" from end).

The wires were then tensile tested to destruction.

\section{$\underline{\text { Results }}$}

I. Breaking stress was higher for tungsten wires exposed to beam than unexposed (virgin) wire as follows:

Stress for exposed wire:

- upstream $=461,600$ PSI mean

- middle $=444,400$ PSI 453,000 PSI 


\section{Description of Tests}

During the months of October and November 1989 tests of 0.002 in dia $x 4$ in length tungsten wires were performed.

a) The wires were taken out from $\mathrm{H}-20$ electrostatic septum after being exposed to the beam. Residual radiation level was $0.8 \mathrm{~m}$ R/HR@12 in. Location of wires removed was as follows:

1. One piece from upstream (specimen 1)

2. One piece from the middle (specimen 2)

3. One piece from downstream (specimen 3 )

b) In addition a number of 6 samples of virgin wires was tested under similar conditions to determine whether any changes occurred due to the beam exposure.

c) The tests performed followed the General Tensile Test Procedure of: Automated Materials Testing system U4.05a (sce annexes \# 1 \& 2).

d) Several attempts were made to determine whether changes took place in the structure of tungsten wire after being exposed to the beam. To accomplish that, the wire samples were photographed as follows: (see annexes A, B, C, D \& E).

- wire unmounted - mag. $400 \mathrm{x}$, photo $\mathrm{A}$ (photo taken $\approx 3 / 4^{\prime \prime}$ from end of wire of an untouched area by the beam.)

- wire unmounted - mag 400x, photo $\mathrm{B}, \mathrm{C} \& \mathrm{D}$ (photos taken $\approx$ at center, area touched by the beam)

- wire mounted and polished - mag 400x, photo E. (Photo taken 1 1/2" from end).

The wires were then tensile tested to destruction.

\section{$\underline{\text { Results }}$}

I. Breaking stress was higher for tungsten wires exposed to beam than unexposed (virgin) wire as follows:

Stress for exposed wire:

- upstream $=461,600$ PSI mean

- middle $=444,400$ PSI 453,000 PSI 
Stress for virgin wire:

- $\max =427,200$ PSI mean

$-\min =324,700$ PSI 384,484 PSI

Variation $\rightarrow+17.8 \%$ (higher stress for exposed wire)

II. Displacement at peak was higher for virgin wire than for exposed wire as follows:

Displacement for exposed wire:

- upstream $=.03900$ in mean

- middle $=.04000$ in .0395 in

Displacement for virgin wire:

$-\max =.05300$ in mean for 6

$-\min =.03800$ in samples $=.048 \mathrm{in}$

variation $-21.5 \%$ (greater displacement for virgin wire)

III. No reliable results were obtained regarding the structure because mounting and polishing with present methods were unrealistic and for initial viewing the photos taken don't show the real shape of wire because the wires were not flat (see metallography report \#3).

\section{Conclusion}

\section{The energy at break decreased for exposed wire by $30 \%$ from:}

.024650 Lbs-in (mean value for virgin wire) to

.018895 Lbs-in (mean value for exposed wire)

This change is probably not significant in that the wires are suspected to break as a result of high temperature induced by direct impingement of the beam. The temperature reached is unknown at this time. The stress induced from the mounting spring tension is $115,000 \pm 10,000$ psi., therefore, the room temperature safety margin is 3.34 for the virgin wire and 3.94 for the exposed wire. It may be possible to reduce the mounting spring tension but an estimate or measurement of the maximum temperature, the wire reaches when hit by the beam is needed to determine if it can withstand the spring tension at high temperature.

Finally, in order to determine a lower value for the spring tension, one has to further investigate the field variation when the wires tend to bow due to reduced tension. 


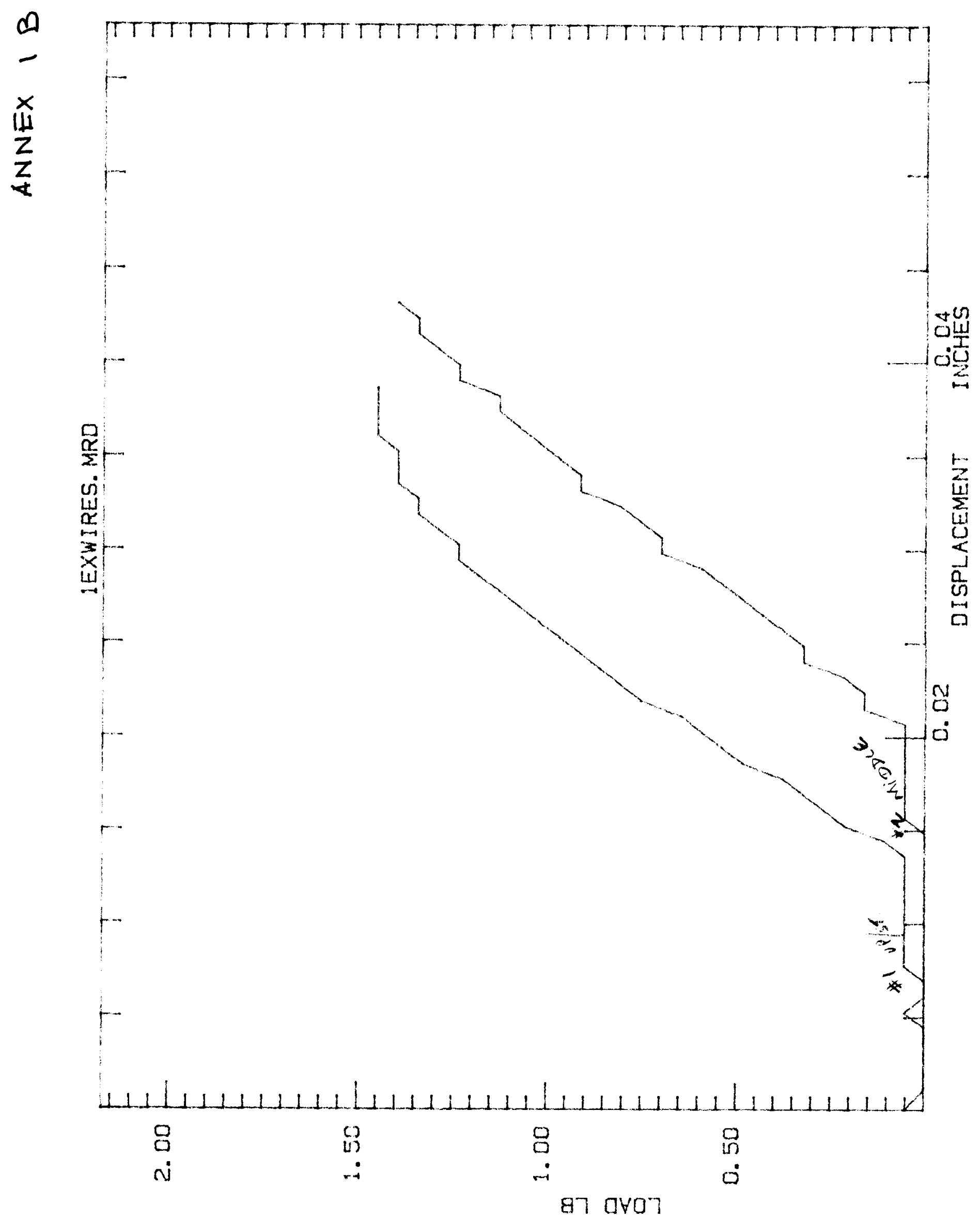


General Tensile Iest - US Custonary Units

Test type: Tungsten vire

Operator nane: Don Horne

Salple Ideatification: 1WIIRB

Interface Iype: 4200 Series

Hachine Paraneters of test:

Sauple Rate (pts/sec): 10.00

Crosshead Speed (in/rin ):

.500

Instros Corporation

Series II Autonated Materials Testing Systen 74.05a

Test Date: Septenber 19,1989

Sanple Type: nire

Huaidity (6): 50

Tesperature (deg. 8): 73

Jested for Viorel Badea

Scc't

ILR I

Dineasions:

Spec. 1 Spec. 2 Spec. 3 Spec. 4 Spec. 5 Spec. 6

Dianeter (in)

.002000 .002000 .002000 .002000 .002000 .002000

Gauge length (in)

$\begin{array}{lllllll}4.0000 & 4.0000 & 4.0000 & 1.0000 & 4.0000 & 4.0000\end{array}$

Out of 6 specinens, 0 excluded.

\begin{tabular}{|c|c|c|c|c|c|c|c|c|c|c|}
\hline $\begin{array}{l}\text { Specinea } \\
\text { lumber }\end{array}$ & 1Haire & $\begin{array}{l}\text { Load } \\
\text { at } 0.2 \% \\
\text { Yield } \\
\text { (1bs) }\end{array}$ & $\begin{array}{l}\text { Stress } \\
\text { at } 0.24 \\
\text { Yield } \\
\text { (psi) }\end{array}$ & $\begin{array}{l}\text { Displcuent } \\
\text { at } 0.2 \% \\
\text { Yield } \\
\text { (in) }\end{array}$ & $\begin{array}{l}\text { X Strain } \\
\text { at } 0.2 \% \\
\text { Yield } \\
(x)\end{array}$ & $\begin{array}{c}\text { Load } \\
\text { at } \\
\text { Peak } \\
\text { (lbs) }\end{array}$ & $\begin{array}{c}\text { Stress } \\
\text { at } \\
\text { Peak } \\
\text { (psi) }\end{array}$ & $\begin{array}{c}\text { Displcuent } \\
\text { at } \\
\text { Peak } \\
\text { (in) }\end{array}$ & $\begin{array}{c}\text { X Strain } \\
\text { at } \\
\text { Peak } \\
(\text { (b) }\end{array}$ & $\begin{array}{l}\text { Load } \\
\text { at } \\
\text { Break } \\
\text { (lbs) }\end{array}$ \\
\hline 1 & & ............. & - & - & - & 1.020 & 324700 . & .04000 & 1.0000 & 1.020 \\
\hline 2 & & - & - & - -.--o-_... & -............ & 1.020 & 324700 . & .03800 & .9500 & 1.020 \\
\hline 3 & & 1.235 & 393100 . & .04533 & 1.1380 & 1.342 & 427200. & .05500 & 1.3750 & 1.342 \\
\hline 4 & & 1.181 & 376000. & .03488 & .8720 & 1.342 & 427200 . & .05000 & 1.2500 & 1.342 \\
\hline 5 & & 1.181 & 376000 . & .04195 & 1.0490 & 1.342 & 427200 & .05300 & 1.3250 & 1.289 \\
\hline 6 & & & & & & 1.181 & 376900 . & .05200 & 1.3000 & 1.181 \\
\hline
\end{tabular}

Hean:

384500. $.04800 \quad 1.2000 \quad 1.299$

Standard

Deviation:

\begin{tabular}{|c|c|c|c|c|c|c|c|}
\hline pecinen & $\begin{array}{c}\text { Stress } \\
\text { at } \\
\text { Break } \\
\text { (psi) }\end{array}$ & $\begin{array}{c}\text { Displcuent } \\
\text { at } \\
\text { Break } \\
\text { (in) }\end{array}$ & $\begin{array}{c}\text { Strain } \\
\text { at } \\
\text { Break } \\
(\mathbf{x})\end{array}$ & $\begin{array}{l}\text { Kung s } \\
\text { (koi) }\end{array}$ & $\begin{array}{c}\text { Beergy } \\
\text { at } \\
\text { Pield } \\
\text { (lbs-in) }\end{array}$ & $\begin{array}{c}\text { Energy } \\
\text { at } \\
\text { Break } \\
(\text { lbs-in })\end{array}$ & \\
\hline 1 & 324700 . & .03928 & .9820 & 4160 & .01449 & .01449 & \\
\hline 2 & 324700 . & .03751 & .9378 & 51460 & .01382 & .01382 & \\
\hline 3 & 127300 & .05220 & 1.3050 & 61610. & .02558 & .03413 & \\
\hline 1 & 127300 . & .04905 & 1.2260 & 8000. & .01964 & .03752 & \\
\hline 5 & 410200. & .05028 & 1.2570 & 8160. & .01996 & .03043 & \\
\hline
\end{tabular}

$\begin{array}{lllllll}6 & 376000 & .04926 & 1.2310 & 01754 & .01754\end{array}$

Hean: $\quad 381700 . \quad .04626 \quad 1.1570 \quad 01851 \quad .02465$

Standard

Depiation: $47930 . \quad .00622 \quad .1555 \quad .00430 \quad .01058$ 

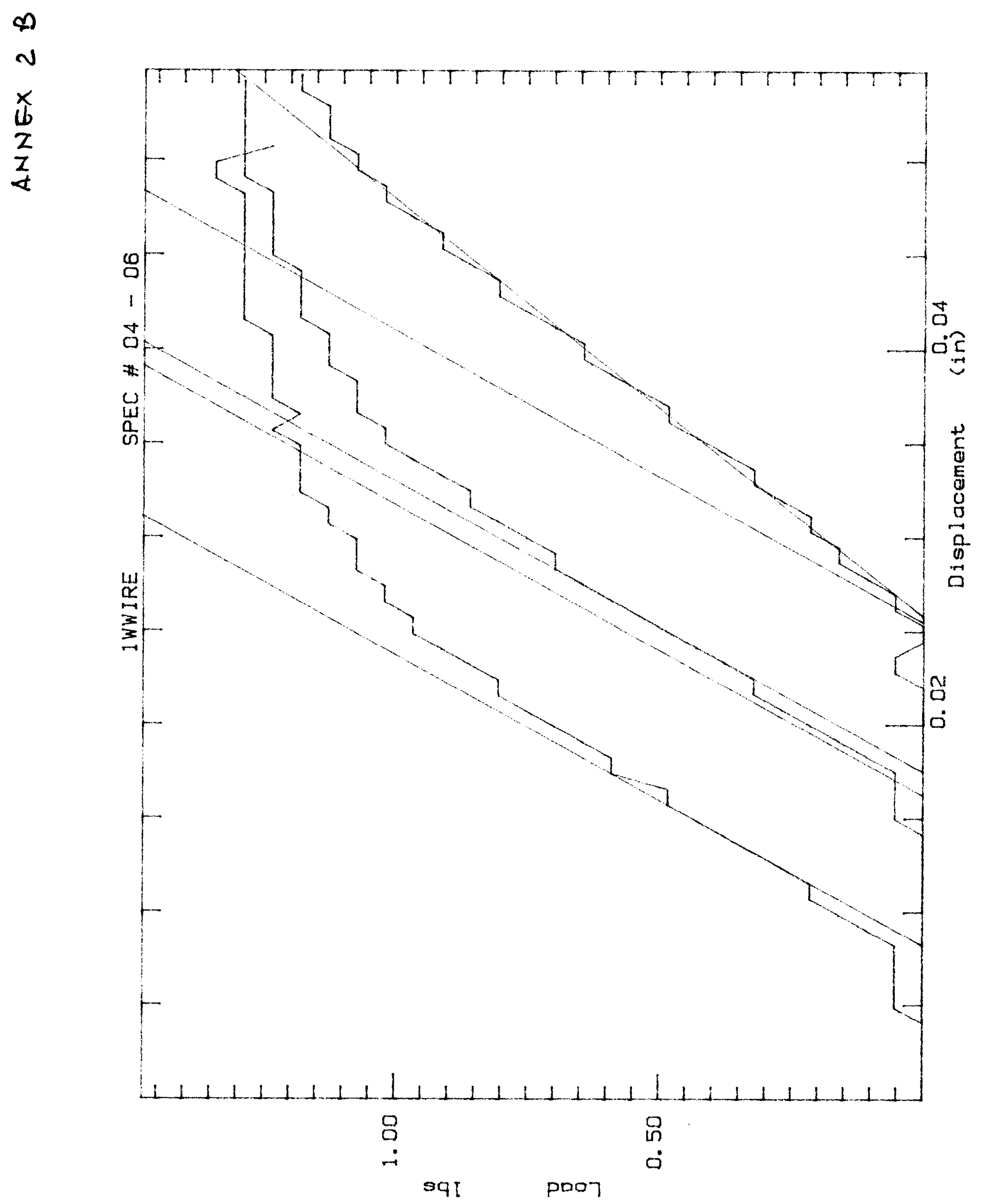
N

$x$
$b$
$z$
$z$
$t$

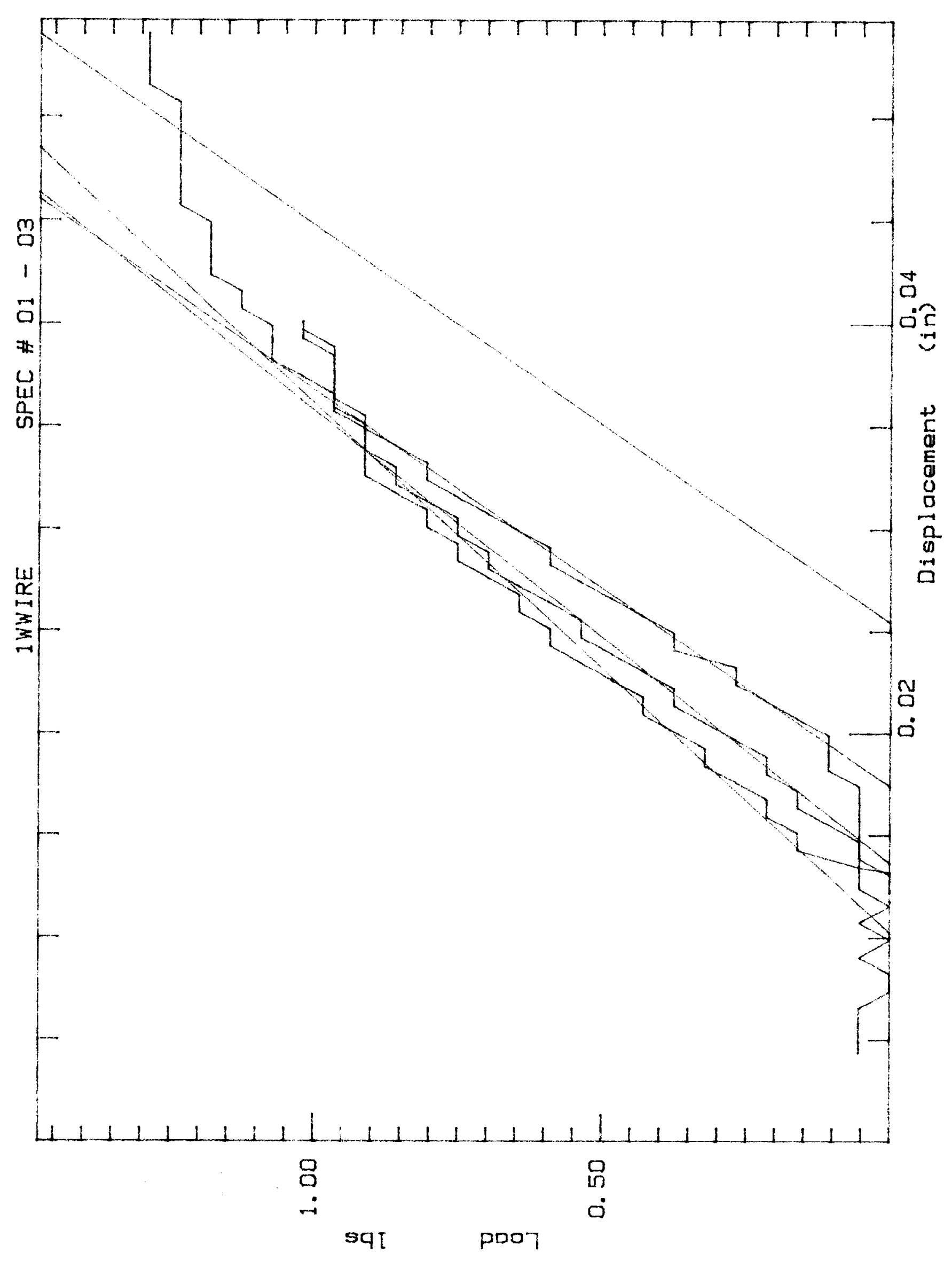


0
$N$
$x$
11
7
$z$
4

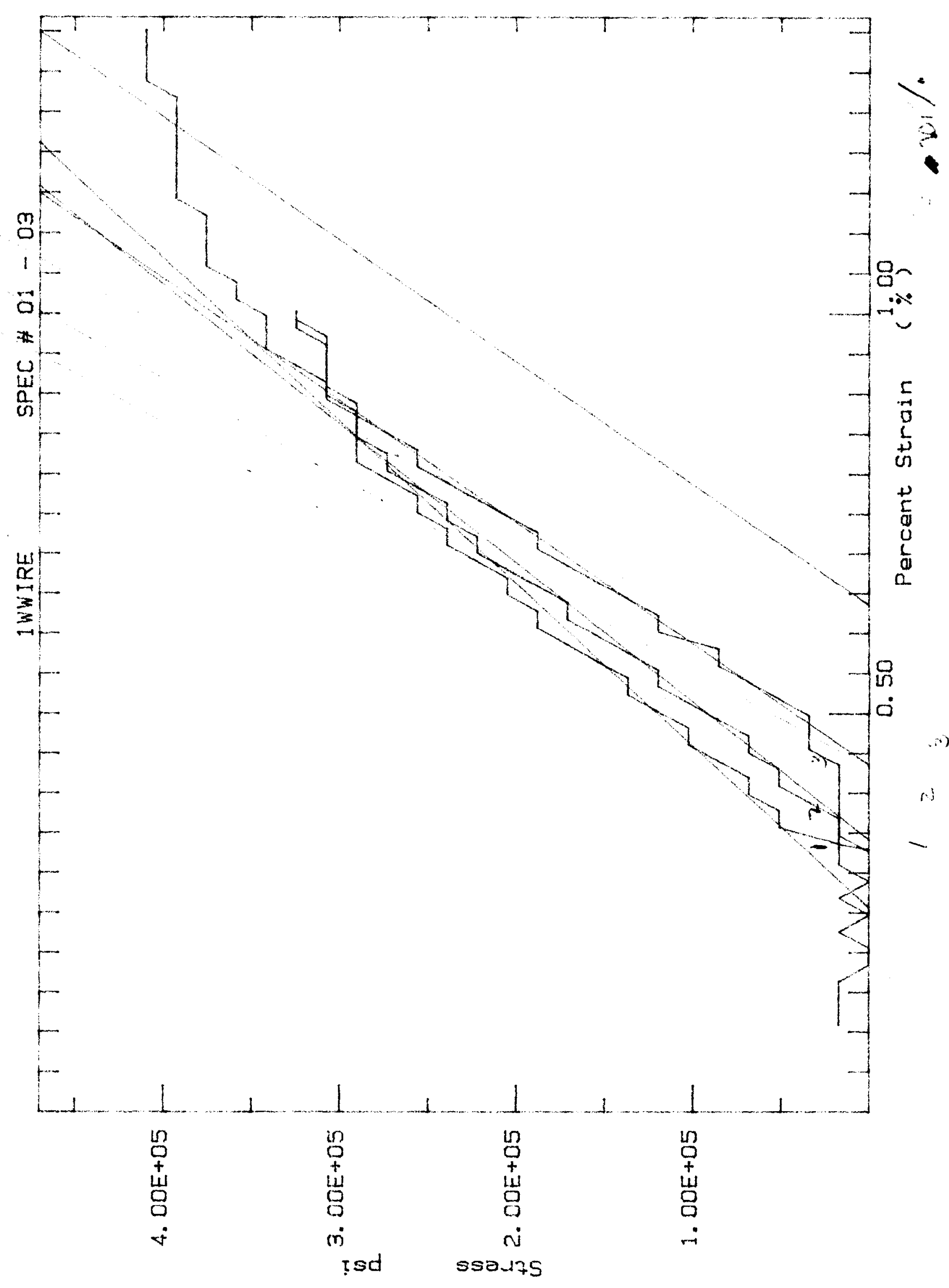




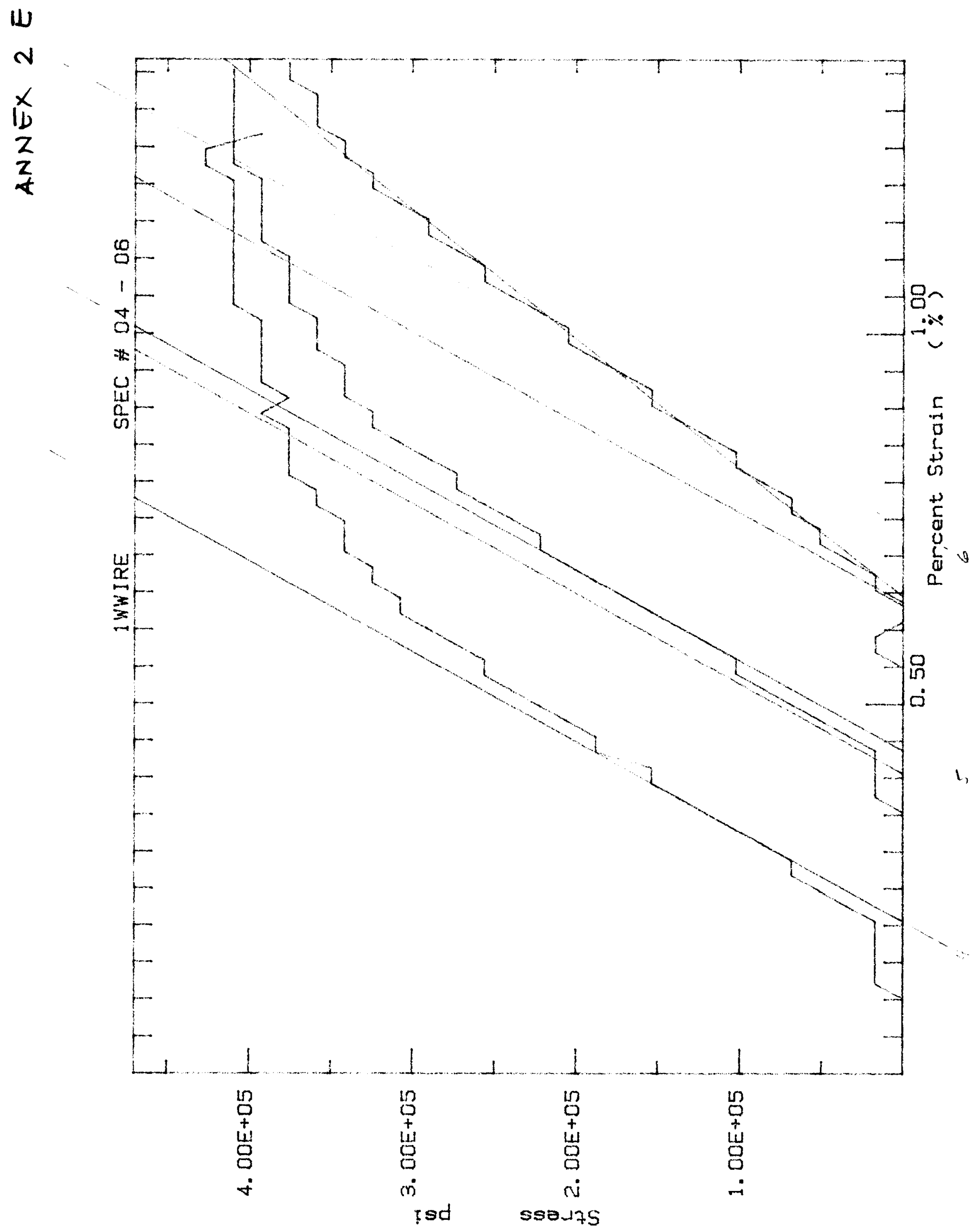


METALLOGRAPHY REPORT

ANNEX 3

Requested by: Visored Bated . Date 12-15.89

description Tungsten Wire O.00: in Bia

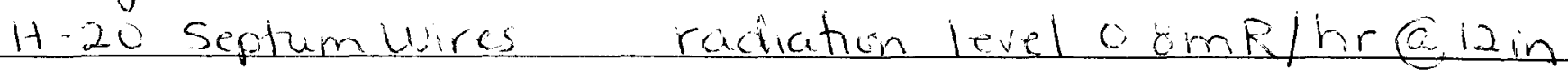

photographed wore (initial viewing)

mounted wire to enable polishing, etching,

longitudinal crossoction viewing

observations Initial viewing was difficult because wire was not flat. Took several photos (ABC D)

Mounting and polishing unrealistic with present methods. Proceclere followed, but due to small diameter wire, polishing caused wire te poll out of mount. one Photo wastakin (E)

PHOTO

A
Description

Wire, unmounted

Phot taken $\approx 3 / 4$ inch from end
Mag

$400 \times$

B) Lore, unirounted

C $\}$ Photo, taken $\approx$ at center $400 x$

D)

E Wire, mounted a polisher 400x Photo taken $\approx 112$ inch from end

prepared by to Warburton 

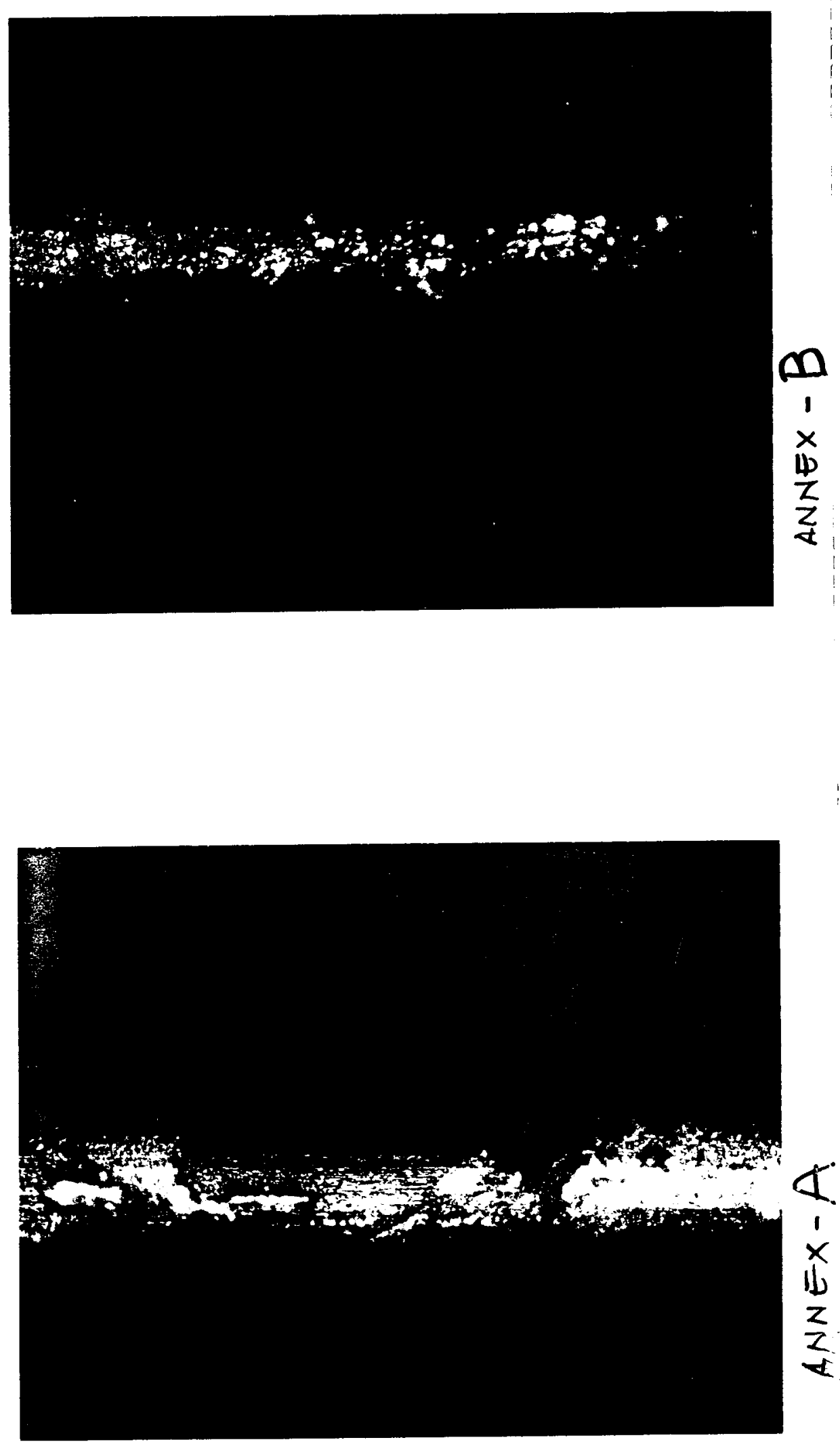

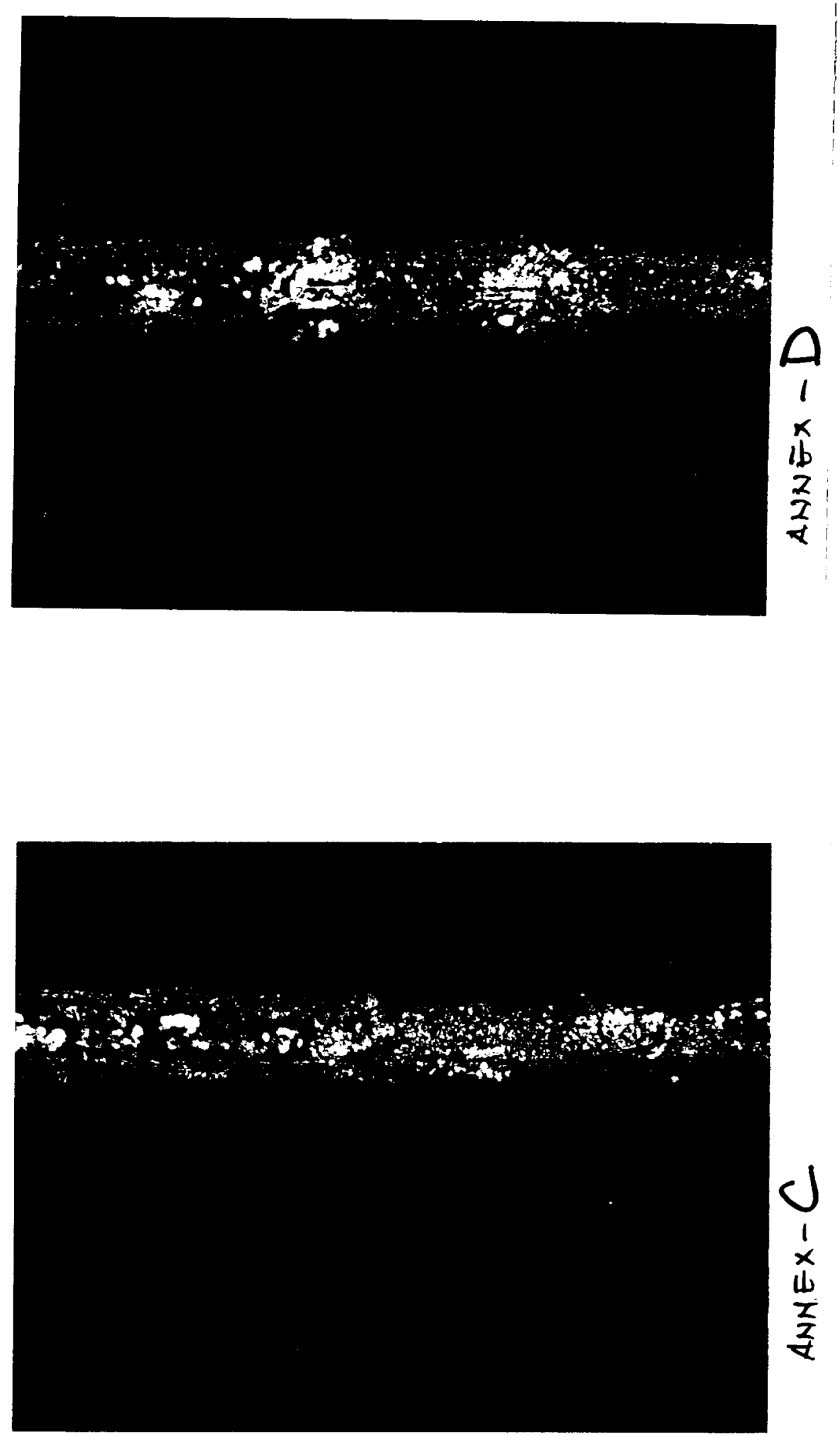


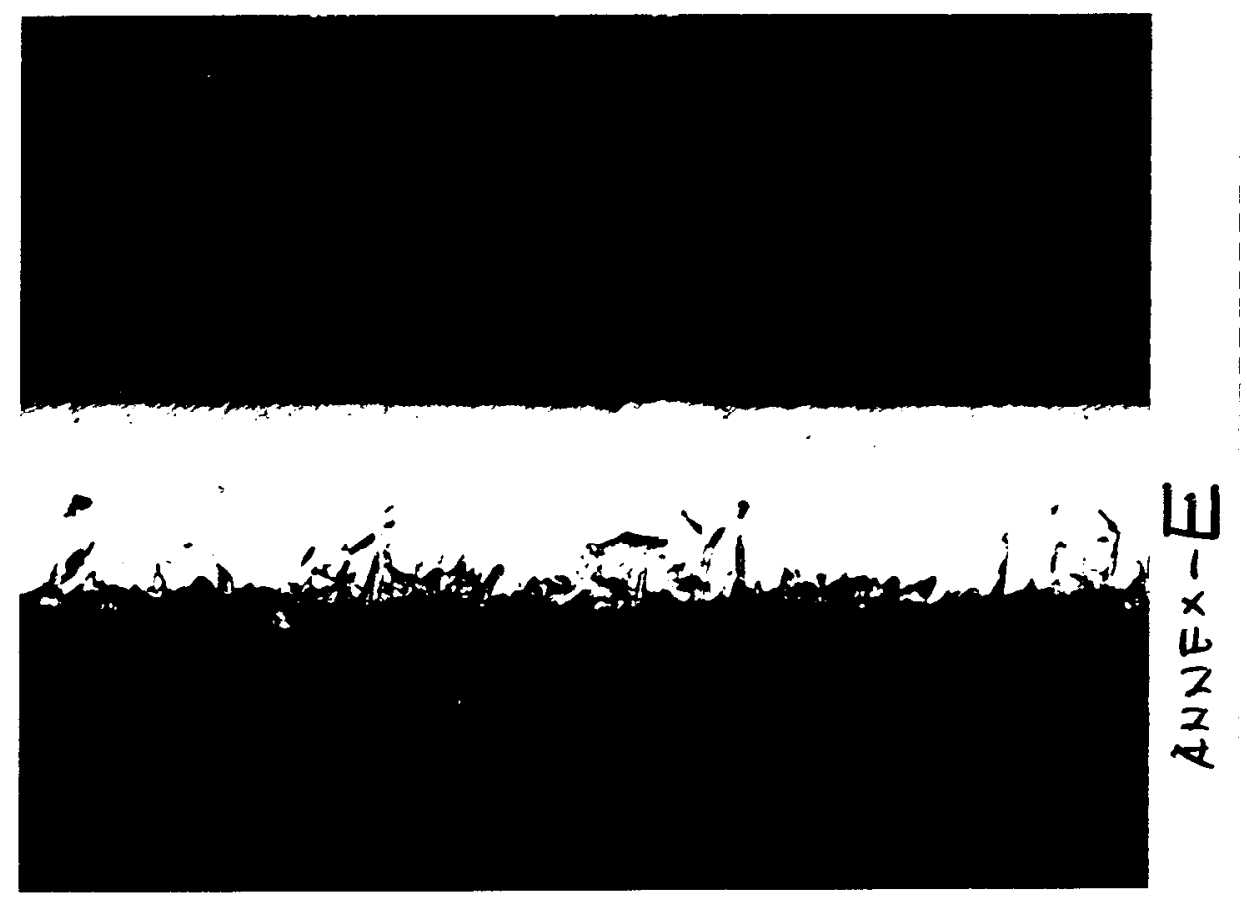

